\title{
La regulación de suelo como componente del derecho a la ciudad (Argentina, 2004-2015)
}

\author{
Land regulation as a component of the right to the city \\ (Argentina, 2004-2015)
}

\author{
María Soledad Arenaza* y María Laura Canestraro** \\ Fecha de recepción: 01-05-2017 - Fecha de aceptación: 18-07-2017 \\ Hábitat y Sociedad (ISSN 2173-125X), n. ${ }^{\circ}$ 10, noviembre de 2017, pp. 289-302. \\ http://dx.doi.org/10.12795/HabitatySociedad.2017.i10.16
}

\begin{abstract}
The regulation of access to land constitutes a fundamental component of the guarantee of the right to the city and, at the same time, its main obstacle. This was evidenced in the public policies implemented in Argentina during the period 2004-2015 that, even in the context of the increase of the state interventions in the housing problem, found their limitations in the access to the land.

As a correlate of this dilemma, there are several explanations that converge in the idea that the State did not advance substantially in modifications to the right of property, constituting itself as one of the main impediments in the guarantee of the right to the city. The purpose of this article is to discuss this perspective, analyzing various regulations to the property rights produced in recent years that function as interstices in this direction, and from them, to qualify that argument.
\end{abstract}

\section{Key words}

Access to land, Regulations, Right to the city

\section{Resumen}

La regulación del acceso al suelo constituye un componente fundamental de la garantía del derecho a la ciudad y, al mismo tiempo, su principal obstáculo. Esto se evidenció en las políticas públicas implementadas en Argentina durante el período 2004-2015 que, aún en el marco del incremento de las intervenciones estatales en la problemática habitacional, encontraron sus limitaciones en el acceso al suelo.

Como correlato de esta encrucijada existen diversas explicaciones que confluyen en la idea de que el Estado no avanzó sustancialmente en modificaciones al derecho de propiedad, constituyéndose este como uno de los principales impedimentos en la garantía del derecho a la ciudad. El propósito de este artículo es poner en debate esta perspectiva, analizando diversas regulaciones al derecho de propiedad producidas en los últimos años que funcionan como intersticios en este derrotero y, a partir de ellos, matizar aquel argumento.

\section{Pallabras clave}

Acceso al suelo; Regulaciones; Derecho a la ciudad

\footnotetext{
* Abogada especialista en Derechos Sociales y Hábitat. Los Robles s/n-Bosque Peralta Ramos, (7600), Mar del Plata. C.e.: sole_ar@ hotmail.com.

** Consejo Nacional de Investigaciones Científicas y Técnicas/Centro de Estudios Sociales y Políticos-Universidad Nacional de Mar del Plata (CONICET-CESP/UNMDP). C.e.: mlcanestraro@gmail.com.
} 


\section{Introducción}

La regulación del suelo constituye uno de los principales obstáculos para el derecho a la ciudad ${ }^{1}$ en Argentina. Desde el proceso de formación de los Estados Nacionales en toda América latina, las instituciones del libre mercado y los derechos de propiedad se vieron fuertemente favorecidos para poder garantizar la reproducción de acumulación de capital (Salazar, 2012). Con la aparición del Estado de bienestar en el siglo $\mathrm{xx}$, las tensiones y contradicciones que ello generaba para las políticas públicas fueron contrarrestadas con lógicas regulatorias redistributivas. Sin embargo, con la crisis del Estado Social y la posterior reestructuración neoliberal, la lógica regulatoria pasó a ser predominantemente competitiva, sujeta a la disciplina de mercado. En este nuevo contexto, se intensificó la mercantilización de todos los aspectos de la vida social, de la mano de instrumentos financieros especulativos orientados a allanar nuevos nichos de acumulación de capital (Brenner, Peck y Theodore, 2011). Desde entonces, ha persistido una legislación elitista y excluyente, que no condice con los procesos reales de producción de las ciudades en América latina y que ha reforzado una dinámica de segregación, incrementando las situaciones de informalidad urbana y favoreciendo las prácticas especulativas (Fernandes, 1999, 2003; Rolnik, 1996).

Como contracara de estos procesos, hacia fines del siglo $\mathrm{xx}$, distintos países de la región comenzaron a bregar por la materialización de una reforma urbana que garantizara el derecho a la ciudad bajo la adopción de nuevas regulaciones, en las cuales, tanto la planificación del territorio como los usos del suelo, cobran centralidad. En ese marco, y destacándose las experiencias de Brasil y Colombia, ${ }^{2}$ surgen diversos debates que ponen en cuestionamiento el rol del mercado en el ordenamiento del territorio, promoviendo la adopción de nuevos instrumentos regulatorios que reviertan la ausencia de límites a la concentración del suelo y a la especulación inmobiliaria y permitan el desarrollo de políticas que fomenten el acceso a la tierra para los grupos más desaventajados, a la luz de la función social de la propiedad (Abramo, 2003; Duhau, 2002; Fernandes, 1998, 1999; Maldonado, 2004; Maldonado y Smolka, 2003; Morales Schechinger, 2003; Smolka, 2003; Smolka y Mullahy, 2007).

En Argentina se constituye en 2005 el Movimiento por la Reforma Urbana, ${ }^{3}$ que derivará posteriormente en la creación de "Habitar Argentina", una iniciativa multisectorial por el derecho a la Tierra, la Vivienda y el Hábitat, orientada a generar diversos proyectos de ley para promover el acceso al hábitat y a la vivienda. También en el contexto local emerge una discusión creciente, aunque aún primigenia, sobre nuevas regulaciones urbanas (Clichevsky, 2001; Cravino, 2006; Scatolini, 2011; Canestraro, Guardia y Layus, 2014; Baer, 2016) en la que la inexistencia de una ley de ordenamiento territorial a nivel federal, en coexistencia con un derecho de dominio civilista de matriz liberal, son señaladas como dos de los principales impedimentos en la garantía del derecho a la ciudad (Arenaza y Duarte, 2010; Maurino, 2012; Tedeschi, 2012; Levenzon, 2014).

En efecto, la imposibilidad de lograr la sanción de un marco normativo de ordenamiento territorial, como el propuesto por el Poder Ejecutivo en 2009, y de incorporar el principio de la función social de la propiedad en la reforma al Código Civil de 2014, reforzó la idea de que en la última década no se produjeron modificaciones sustantivas a 
la regulación del suelo desde un enfoque de derechos (CELS, 2015a), fortaleciéndose incluso el paradigma liberal del derecho de propiedad. ${ }^{4}$ Frente a esto, y aun asumiendo que la estructura de la propiedad de la tierra no fue modificada sustancialmente desde el proceso de organización nacional (Fernández Wagner, 2012), el propósito de este ensayo es visibilizar la existencia de diversos intersticios legales que permitirían avanzar en la redistribución y el acceso al suelo de los y las habitantes de nuestro país. Para ello, se analizan diversas normativas producidas en el período de referencia que, lejos de constituirse como un corpus normativo en términos de su sistematicidad, fueron seleccionadas en función del objeto propuesto. ${ }^{5}$ Estos matices, además, dan cuenta de que tal producción normativa, lejos de ser lineal, es más bien compleja y, por momentos, contradictoria.

Con ese criterio, a continuación presentamos dos discusiones centrales en torno a la regulación del suelo, cuya rigidez impide un cambio de paradigma en las políticas de ordenamiento territorial. Luego nos centramos en el análisis de la producción de normativa reciente sobre limitaciones al derecho de propiedad y que abren un escenario de posibilidades para la progresiva garantía del derecho a la ciudad.

\section{Las "grandes" discusiones nacionales}

\section{"El crecimiento armónico de la Nación"}

La "Cláusula del Desarrollo Humano", incorporada a la Constitución Nacional en la última reforma de 1994, le encomienda al Congreso "proveer al crecimiento armónico de la Nación y al poblamiento de su territorio" y "promover políticas diferenciadas que tiendan a equilibrar el desigual desarrollo relativo de provincias y regiones" ${ }^{6}{ }^{6} \mathrm{El}$ cumplimiento de este mandato presupone el dictado de una Ley Federal que establezca presupuestos mínimos de ordenamiento territorial, compatibilizando los objetivos, principios e instrumentos de esta política, con un abanico de derechos fundamentales cuyo goce está asociado indivisible e interdependientemente al desarrollo del territorio.

El primer desafío y, a su vez, la primera resistencia a los que se enfrenta la adopción de esta norma es la de recuperar el rol del Estado en el ordenamiento del territorio, asumiendo esta tarea como una función pública indelegable. Esto significa poner en agenda a la planificación territorial a fin de orientar el proceso de producción social del espacio, al cumplimiento de los objetivos que establece la cláusula de desarrollo humano. En esta clave, la planificación debería tender a revertir la fragmentación socio-territorial causada por las fuertes desigualdades que presentan el acceso a la tierra, a la vivienda y a los equipamientos, infraestructuras y servicios urbanos, entre las distintas regiones, provincias, ciudades y barrios del país.

Desde ya que poner en agenda a la planificación del territorio requiere no solo de una Ley Federal que determine presupuestos mínimos de ordenamiento territorial, ${ }^{7}$ sino de un cambio de paradigma en la intervención del Estado en todos sus niveles, dentro del marco de competencias que deben ejercer las provincias y los municipios en materia de regulación y planificación del territorio (Arenaza y Duarte, 2010). En tal sentido, vale señalar que, de 24 provincias, solo Buenos Aires (Decreto Ley 8912/77) y Mendoza (Ley 8051/09) cuentan con un marco normativo que regula el ordenamiento territorial y los usos
4 Highton de Nolasco, E. El derecho de propiedad en el nuevo código civil y comercial de la Nación. Recuperado el 10 de noviembre de 2016 de: http:// www.nuevocodigocivil.com/wp-content/ uploads/2015/02/El-derecho-de-propiedad-en-el-nuevo-Codigo-Civil-y-Comercialde-la-Nacion.-Por-Elena-I.-Highton.pdf. 5 Ver Anexo 1.

6 El artículo 75 inc. 19, segundo párrafo de la Constitución, establece: "Atribuciones del Congreso: Proveer lo conducente al desarrollo humano, al progreso económico con justicia social, a la productividad de la economía nacional, a la generación de empleo, a la formación profesional de los trabajadores, a la defensa del valor de la moneda, a la investigación y al desarrollo científico y tecnológico, su difusión y aprovechamiento./ Proveer al crecimiento armónico de la Nación y al poblamiento de su territorio; promover políticas diferenciadas que tiendan a equilibrar el desigual desarrollo relativo de provincias y regiones. Para estas iniciativas, el Senado será Cámara de origen".

7 A los fines del presente ensayo entenderemos al ordenamiento territorial como una actividad técnico-política que permite tomar decisiones en materia de política territorial, ambiental y urbana, para lograr que el proceso de producción social del espacio se desarrolle en un determinado sentido. 
8 Esta información surge de una encuesta realizada por el Centro de Investigación de Política Urbana y Vivienda de la Universidad Torcuato Di Tella sobre regulación de usos del suelo a $190 \mathrm{mu}-$ nicipios a nivel nacional durante el año 2011. Recuperado el 10 de noviembre de 2016 de: http://www.utdt.edu/ver_contenido.php?id_contenido=8276\&id_item_ menu=16128. Incluso Clichevsky (1999) señala que hasta la década de los noventa no existió una política urbana explícita vinculada a la problemática del suelo urbano, si bien se produjeron diversas modificaciones constitucionales con la reforma en 1994, estas se subsumieron al derecho a la vivienda, pero no problematizaron la cuestión del acceso al suelo.

9 El coordinador de la Comisión de Legislación del COFEPLAN remarcó la importancia de esta dimensión al explicar el anteproyecto de Ley Nacional de Ordenamiento Territorial promovido por el Poder Ejecutivo en 2009, vid.: http://www. cafedelasciudades.com.ar/planes_politica_91.htm.

10 Harvey $(2004,2008)$ caracteriza este proceso como "la acumulación de bienes naturales por desposesión, por medio de una nueva espacialidad del capital". Estas prácticas desposesorias también tienen su correlato en lo urbano, provocando el desplazamiento de poblaciones de baja renta que han vivido históricamente en zonas hoy degradadas, en vistas a viabilizar proyectos de redesarrollo urbano orientados a capturar suelo potencialmente valioso. Como dice Harvey (2004), "esta es la historia de la destrucción creativa (con todas sus consecuencias sociales y ambientales negativas) inscrita en la evolución del paisaje físico y social del capitalismo" (p. 103).

11 Recuperado el 10 de noviembre de 2016 de: http:/ /www.cofeplan.gov.ar/ html/doc_institucionales/doc/anteproyecto.pdf.

12 El anteproyecto de Ley Nacional de Ordenamiento Territorial definía el Plan Estratégico Territorial Nacional en su artículo 14 como el "producto de un proceso de construcción coordinado por el Estado Nacional, mediante la formación de consensos con las jurisdicciones provinciales y la Ciudad Autónoma de Buenos del suelo a nivel provincial, promoviendo y condicionando la adopción de planes a nivel municipal. Por su parte, mientras los municipios exhiben un mayor desarrollo de marcos regulatorios en materia de usos del suelo, la gran mayoría de esta regulación fue aprobada en las décadas de los setenta y ochenta. ${ }^{8}$

Ahora bien, la institucionalización de la planificación es una condición necesaria, pero insuficiente, para poder incidir en los procesos de ocupación, conservación, transformación y uso del suelo, en el sentido de lograr un territorio equilibrado, sustentable y socialmente justo. Para esto es necesario que la noción de "suelo" sea objeto de una reconceptualización jurídica, a través de la cual este bien incorpore una dimensión social, además de la meramente económica que le ha sido asignada por los derechos reales y, particularmente, por el derecho de dominio.

Hasta el momento, la Ley General del Ambiente n. ${ }^{\circ} 25675$ ha sido prácticamente la única "puerta de entrada" al ordenamiento del territorio, que permite regular el uso y ocupación del suelo incorporando la dimensión ambiental de la tierra como un límite a la lógica del mercado. Sin embargo, resta conceptualizar al suelo como un recurso social e integrar la política ambiental nacional a una política de planificación territorial que promueva un ordenamiento sustentable en el ámbito urbano y rural, resguardando no solo los derechos de incidencia colectiva que se vinculan a la función ambiental del suelo, sino también a aquellos que se enlazan con su función social, como el derecho a un hábitat digno y a la ciudad. ${ }^{9}$

Desde ya no debe perderse de vista que la operatividad de los objetivos y principios establecidos en la Ley General del Ambiente se debió, fundamentalmente, a la inclusión de instrumentos de la política y la gestión ambiental. La evaluación de impacto ambiental y la contratación de un seguro ambiental, por ejemplo, tornan operativo el objetivo de prevenir y recomponer el daño ambiental. Siguiendo esta misma lógica, el dictado de una Ley Federal que establezca presupuestos mínimos de ordenamiento territorial debe prever instrumentos de gestión urbana que sirvan para concretar los objetivos del planeamiento territorial en cada una de las jurisdicciones.

En síntesis, una ley de ordenamiento territorial implica un reacomodamiento de competencias entre el Estado y el mercado, poner en agenda a la planificación territorial, reconceptualizar la noción jurídica de "suelo" y dotar de instrumentos a las políticas urbanas. Todo ello pone en tensión la matriz productiva del país, basada en el agronegocio y caracterizada por la expansión del capital agrario en zonas y provincias con una irregularidad estructural en la tenencia de la tierra y por la expulsión de los sectores de más bajos recursos hacia lugares cada vez más alejados de las ciudades y de baja calidad urbana (CELS, 2015a). ${ }^{10}$

Como evidencia de esto, en el año 2009, el Poder Ejecutivo de la Nación impulsó un borrador de anteproyecto de Ley Nacional de Ordenamiento Territorial con especial énfasis en la institucionalización de la planificación. ${ }^{11}$ En líneas generales, este preveía la obligatoriedad de cada provincia y de la Ciudad de Buenos Aires de realizar planes de ordenamiento territorial, determinaba los contenidos mínimos que estos debían desarrollar, confería al Plan Estratégico Territorial Nacional $(\mathrm{PET})^{12}$ un rango legal y creaba una nueva institucionalidad de alcance federal (el Consejo Federal de Planificación y Ordenamiento Territorial (COFEPLAN), con el objetivo de participar en la planificación, 
articulación e implementación de la política territorial que comprometieran la acción conjunta de la Nación, las provincias y la Ciudad Autónoma de Buenos Aires. En segundo término, este anteproyecto redefinía la noción de "suelo" al reconocerlo como un "recurso natural, económico y social". ${ }^{13}$ En base a ello, el uso y la disposición del suelo podían verse restringidos conforme a su destino y/o, en ciertos casos, estar acompañados de algún tipo de obligación a cargo del titular del derecho de dominio, con el objetivo de compatibilizar el ejercicio de este derecho individual con los derechos de incidencia colectiva y con la protección del interés general. Por último, se enunciaban una serie de instrumentos específicos de la política, optativos para las jurisdicciones, a fin de concretar los objetivos que determinen en sus planes de ordenamiento, enumerando, entre otros, a "la edificación obligatoria de inmuebles ociosos" y "a la participación del Estado en la valorización de inmuebles por acción urbanística" ${ }^{14} \mathrm{El}$ primero materializa la función social del suelo, el segundo, la distribución de los costos y beneficios del proceso de urbanización entre los actores públicos y privados.

Pese a haber sido presentado públicamente y debatido en diversos ámbitos — técnicos, académicos, organizaciones-, este anteproyecto no fue enviado al Congreso para su tratamiento parlamentario, a causa de la resistencia generada por la intervención del Estado en el desarrollo del territorio y la incorporación de la función social a la noción del suelo.

\section{"El derecho de dominio en el Código Civil"}

El derecho de dominio consagrado en la Constitución Nacional, y delimitado posteriormente en el Código Civil, es el derecho real que otorga todas las facultades de usar, gozar y disponer material y jurídicamente de una cosa, dentro de los límites previstos por la ley. Históricamente, fue concebido por el liberalismo jurídico como un derecho de carácter absoluto, perpetuo y exclusivo..$^{15}$

Este andamiaje liberal del derecho de propiedad enfatiza las libertades ilimitadas del titular del dominio frente a sus obligaciones. La perpetuidad implica que este no se extingue, aunque el dueño no ejerza sus facultades, excepto que otro adquiera el dominio por prescripción adquisitiva, es decir, por su posesión en el transcurso del tiempo. Para que esto ocurra, el plazo que necesita quien efectivamente habita un inmueble es de 20 años, ${ }^{16}$ a excepción de que cuente con un justo título, en cuyo caso el plazo se reduce a una década. ${ }^{17}$ Finalmente, la exclusividad está anclada a un derecho que se concibe como individual antes que colectivo, otorgando a su titular la facultad de excluir a terceros.

Esta noción de propiedad dificulta hasta la actualidad toda intervención del Estado en el ordenamiento del territorio, favorece la especulación inmobiliaria y, al mismo tiempo, obstaculiza el avance del derecho a la ciudad. Por estas razones, desde diferentes espacios (organizaciones sociales e instituciones académicas) se viene bregando por la incorporación de la función social de la propiedad al contenido jurídico de los bienes - como el suelo-y/o al ejercicio de los derechos reales - entre los cuales se encuentra el derecho de dominio-. A pesar de ello, esta reconceptualización de la propiedad quedó descartada en la última reforma del Código Civil y Comercial de la Nación, que entró en vigor el 1 de agosto de 2015 (Habitar Argentina, 2012; Arenaza, 2012)..$^{18}$
Aires, que define los lineamientos generales para el logro de un territorio nacional equilibrado, sustentable y socialmente justo. Dichos lineamientos representan al modelo de territorio nacional al que aspiran el conjunto de las jurisdicciones que lo componen, expresando las relaciones entre el medio biofísico, población, actividades económicas y flujos de bienes y personas entre las distintas regiones del país. A su vez, constituyen el fundamento para la articulación y concurrencia de los planes y proyectos de impacto territorial promovidos por los organismos de Gobierno nacional, provincial o municipal”.

13 Ob. cit., 8, art. 1.

14 Ob. cit., 8 , art. 5

15 Código Civil de la Nación Argentina, artículos 1941-4.

16 Código Civil de la Nación Argentina, artículo 1899.

17 Código Civil de la Nación Argentina, artículo 1897.

18 Vale señalar como antecedente que en el artículo 38 de la Constitución de 1949 se sancionó la función social de la propiedad, pero la misma fue derogada en 1956. 
Frente a los altos niveles de informalidad urbana y rural, estas propuestas, además, hacían hincapié en la necesidad de incorporar "alternativas de regularización para las formas de habitar popular" en los casos de prescripción sobre inmuebles para fines de vivienda. ${ }^{19}$ Sin que eso se logre, tampoco se incorporaron otras "herramientas de intervención estatal para resolver el acceso al suelo y al territorio que afectan a cientos de miles familias pobres en áreas urbanas y rurales".

En el ámbito urbano, las "nuevas formas de dominio" incorporadas al Código reconocieron, en cambio, a las "propiedades modernas" 20 bajo la figura de conjuntos inmobiliarios, en la que se engloban los clubes de campo y los barrios cerrados o privados. ${ }^{21}$ De esta manera, mientras "unos se quedaron afuera", el nuevo Código permite regularizar los actuales modos de vivir de los sectores medios y altos (Bercovich, 2012). En simultáneo se introduce el derecho de superficie, ${ }^{22}$ como un nuevo derecho real temporario sobre un inmueble ajeno que otorga a su titular la facultad de usar, gozar y disponer material y jurídicamente de construir en el terreno, haciendo propio lo construido, en coexistencia con la propiedad separada del titular del suelo. Esta figura tuvo una buena recepción entre los desarrolladores inmobiliarios, en virtud de implicar una reducción de la inversión inicial necesaria para los grandes proyectos comerciales al disminuir el costo del suelo. En términos de garantía del derecho a la ciudad, y más concretamente del acceso a la vivienda, existen vastos ejemplos de la persistencia de una cultura patrimonialista que redunda en la centralidad del título de propiedad y, por ende, en la dificultad de viabilizar una práctica de esta índole.

En el ámbito rural, este derecho de superficie formaliza el desdoblamiento entre la propiedad de un campo (titularidad del suelo) y el derecho de plantar o la propiedad de lo plantado, fortaleciendo el capital agrario, en vez de facilitar el acceso al suelo mediante la prescripción adquisitiva de tierras ocupadas con fines de vivienda y producción.

Por último, el nuevo Código redujo de 35 a 15 metros la restricción al dominio de los propietarios de terrenos colindantes con ríos públicos y además suprimió el carácter de calle o camino público de esa franja de terreno. Esta medida implicó una de las mayores privatizaciones del espacio público en el Código Civil, favoreciendo la proliferación de barrios cerrados y countries - por ejemplo, en el Delta bonaerense, los ríos de la Patagonia y la Mesopotamia-y, a su vez, el aniquilamiento de la posibilidad de acceder a estos espacios por parte de los demás ciudadanos (Viale, 2012).

Fuera de beneficiar a los sectores medios y altos, el nuevo Código reproduce el reconocimiento constitucional de los derechos de los pueblos indígenas, en particular el derecho a la propiedad comunitaria de las tierras que tradicionalmente ocupan y de aquellas otras aptas y suficientes para el desarrollo humano (art. 18), aunque remitiendo la operatividad de este derecho al dictado de una ley especial.

En definitiva, y como sintetizó una ministra de la Corte de la Nación, "nada ha cambiado en materia de propiedad en el nuevo Código Civil y Comercial de la Nación. Y si algo ha cambiado, ha sido para favorecerla".

Ahora bien, descartada la función social de la propiedad, el nuevo Código reformula algunos principios generales del derecho que sirven de interpretación al derecho privado, reconoce derechos de incidencia colectiva como el derecho al medio ambiente y el derecho de consumo y sistematiza principios de ambas ramas, lo que en su conjunto 
puede fortalecer el rol del Estado en el ordenamiento del territorio y la regulación del suelo (Lorenzetti, 2012). En rigor, la reforma no se agota en el reconocimiento de estos derechos. Abre la posibilidad de limitar el ejercicio especulativo del derecho de propiedad sobre el suelo, al no amparar el ejercicio abusivo de los derechos individuales, en la medida en que este contraríe un derecho de incidencia colectiva como el derecho a un hábitat digno o a la ciudad..$^{23}$

Esta consideración se refuerza con la exigencia de ajustar el ejercicio de los derechos individuales al derecho administrativo nacional y local dictado en el interés público. ${ }^{24}$ Sin embargo, para hacer operativa esta limitación, resultará necesario que el derecho administrativo nacional o local consagre el derecho a un hábitat digno o la ciudad en sus respectivas leyes de ordenamiento territorial y usos del suelo.

\section{Intersticios I. Límites a la concentración de la tierra y regímenes de excepción a la informalidad}

En el año 2011, el Congreso Nacional sancionó la Ley 26737 de Protección al Dominio Nacional sobre la Propiedad, Posesión o Tenencia de las Tierras Rurales, más conocida como "Ley de Tierras". De acuerdo con el texto de la norma, el primer objetivo de este régimen se centra en "determinar la titularidad, catastral y dominial, de la situación de posesión, bajo cualquier título o situación de hecho de las tierras rurales, y establecer las obligaciones que nacen del dominio o posesión de dichas tierras". ${ }^{25}$ El cumplimiento de este objetivo representaría un avance importante frente a las deficiencias que presentan los sistemas catastrales de algunas provincias, como son: la existencia de registros incompletos, duplicados y/o de áreas provinciales con vacíos importantes de información (Sili y Soumoulou, 2011). En tanto diagnóstico, presupone un relevamiento del estado de situación de las tierras rurales en todo el territorio nacional, abarcando a "todo predio ubicado fuera del ejido urbano, independientemente de su localización o destino" ${ }^{26}$ y sistematizando no solo los derechos de propiedad fornidos de títulos, sino también las situaciones de posesión bajo cualquier título o situación de hecho. Así, el relevamiento de la información abandona la perspectiva normativista, haciéndose eco de la informalidad rural. Finalmente, queda planteada la adopción de una regulación específica en materia de obligaciones vinculadas al ejercicio del derecho de propiedad y/o de los derechos posesorios sobre la tierra de alcance general.

Pese al alcance genérico de este primer objetivo, y a la importancia de su desarrollo para una política de ordenamiento territorial en el ámbito rural, es únicamente el segundo objetivo propuesto por la Ley de Tierras, en cuanto refiere a "regular, respecto de las personas físicas y jurídicas extranjeras, los límites a la titularidad y posesión de tierras rurales, cualquiera sea su destino de uso o producción", ${ }^{27}$ el que acabará plasmado en limitaciones concretas a los derechos posesorios y a la titularidad de la tierra en el ámbito rural, ${ }^{28}$ así como en la creación de un sistema de información, monitoreo y control para la implementación de esta política, ${ }^{29}$ de la mano de un órgano interministerial con representación provincial encargado de ejecutarla.

La operatividad dada a este segundo objetivo es consistente con los fundamentos del proyecto enviado por el Poder Ejecutivo al Congreso. ${ }^{30}$ Sin embargo, el mismo presenta cuestionamientos desde el punto de vista de los derechos fundamentales, por su incongruencia con la
23 Código Civil Argentino, artículo 14. 24 Código Civil Argentina, artículo 241. 25 Ley 26737, artículo 2 inc. a. 26 Ley 26737, artículo 1.

27 Ley 26737, artículo 2 inc. b.

28 Ley 26737, artículos 3-13.

29 Ley 26737, artículos 14-15.

30 En los fundamentos del proyecto enviado por el Poder Ejecutivo Nacional al Congreso se destaca "la necesidad de impedir la consolidación de procesos que podrían comprometer gravemente el desarrollo, la soberanía nacional y la titularidad del pueblo argentino sobre sus recursos estratégicos no renovables, como la tierra y el agua dulce [...], dicha regulación deviene necesaria para frenar el proceso de adquisición de grandes extensiones de tierra por parte de capitales financieros transnacionales, el que se viene profundizando en los últimos años a raíz de la especulación desatada con motivo de la variación de los precios de los productos primarios en el mercado internacional $[\ldots] "$. 
31 Constitución Nacional, artículo 20.

32 Desde otra perspectiva, se argumenta que no habría violación a la garantía de igualdad, puesto que no se impide en modo alguno el ejercicio del derecho a adquirir las tierras por parte de los extranjeros, sino que se restringe su derecho de propiedad en función del interés social y la soberanía de la Nación en sus recursos estratégicos, lo que estaría permitido bajo la Convención Americana de Derechos Humanos. El artículo 21 de la Convención Americana de Derechos $\mathrm{Hu}-$ manos — que versa sobre el Derecho a la propiedad privada-, dice claramente que "toda persona tiene derecho al uso y goce de sus bienes. La ley puede subordinar tal uso y goce al interés social”. Un análisis exhaustivo de la Ley 26737 y la discusión en torno a la categoría extranjero puede leerse en Hermann Guttner (2012). igualdad de derechos entre ciudadanos argentinos y extranjeros consagrada en la Constitución Nacional, ${ }^{31}$ entre los que se incluye el derecho a ejercer el comercio y a adquirir bienes inmuebles. ${ }^{32}$ Desde el punto de vista del ordenamiento territorial y los usos del suelo, la limitación a este último objetivo abandona la posibilidad de proyectarse como una política de ordenamiento territorial de alcance general, reorientando la producción social del espacio rural hacia la diversificación de la matriz productiva, la soberanía alimentaria y la protección de la tierra como recurso natural, económico y social, con independencia del origen del capital que la explote. Aun así, la Ley 26737 no deja de ser un intersticio en un campo signado por la ausencia de presupuestos mínimos de ordenamiento territorial a nivel federal y un derecho de propiedad anclado en una matriz liberal, estableciendo un límite a la concentración de la tierra rural que se proyecta en la ocupación del territorio a futuro.

En la misma encrucijada encontramos a otro tipo de marcos regulatorios sancionados en los últimos 10 años, que operan como regímenes de excepción ante la ausencia de mecanismos de regularización destinados a las formas de habitar y producir de los sectores populares. Es el caso puntual de la Ley 26160, que declara la emergencia en materia de posesión y propiedad de las tierras que tradicionalmente ocupan las comunidades indígenas, y de la Ley 27118, que declara de interés público la agricultura familiar, campesina e indígena. Ambas legislaciones suspenden temporalmente los desalojos que afectan a estos colectivos.

Como medidas de fondo, sendas leyes ordenan la realización de un relevamiento técnico-jurídico-catastral de la situación dominial de las tierras ocupadas por estos colectivos, creando fondos para financiar dicho relevamiento y los programas de regularización dominial. Por su parte, la Ley 27118 crea un Banco de Tierras para la Agricultura Familiar, con el objetivo de contar con tierras aptas para adjudicar en forma progresiva a los agricultores y agricultoras familiares.

El impacto de estos marcos regulatorios, que se constituyen en intersticios a la informalidad dominial, es relativamente incierto en algunos aspectos, mientras que en otros se ha demostrado casi nulo. La mayoría de los jueces desconocen estas leyes y, por ende, no aplican la suspensión de los desalojos a favor de estas comunidades. Con relación a las medidas de fondo, la prórroga de la Ley 26110 evidencia las dificultades que presenta la realización del relevamiento de tierras comunitarias indígenas, que además se limita a las tierras bajo posesión actual, tradicional y pública, sin incluir aquellas tierras de las cuales han sido despojados. Por su parte, la Ley 27118 fue sancionada en 2014 sin grandes avances en su implementación.

\section{Intersticios II. Avance sustancial en la regulación del suelo desde una perspectiva integral}

Como señalábamos anteriormente, Buenos Aires es una de las dos provincias de la Argentina que cuenta con una ley de ordenamiento territorial: el Decreto-Ley de Uso de Suelo 8912 de 1977, mediante el cual se fijan condiciones para la producción del suelo urbano, introduciendo restricciones y exigencias en cuanto a la zonificación, el tamaño de los lotes y las obras de infraestructura, entre otros. Ello trae consigo un doble efecto: el encarecimiento de la tierra y, como corolario, el crecimiento de la informalidad urbana, al no prever mecanismos que garanticen el acceso al suelo urbanizado de aquellos sectores que no 
pueden afrontar sus costos. Lo paradójico es que la mayoría de la producción normativa realizada a posteriori se ha sustentado en excepciones a la 8912, no solo legitimando la trasgresión, sino legalizando su excepcionalidad. ${ }^{33}$

Pero las mayores regulaciones sobre el acceso al suelo se vinculan a la Ley de Acceso Justo al Hábitat (14449), sancionada en 2012, que asume la complejidad del déficit urbano habitacional desde una perspectiva integral mediante políticas urbanas y habitacionales basadas en cuatro principios: el derecho a la ciudad y a la vivienda, la función social de la propiedad, la gestión democrática de la ciudad y el reparto equitativo de cargas y beneficios. ${ }^{34}$

A los efectos de garantizar la operatividad de dichas políticas, la ley establece un conjunto de instrumentos de actuación orientados a resolver el déficit urbano-habitacional existente, como la integración socio-urbana de villas y asentamientos precarios o el fomento del crédito para la mejora del hábitat. Otros instrumentos regulados en la norma, como la promoción de procesos de producción social del hábitat y de urbanizaciones planificadas, las zonas de promoción del hábitat social y la participación en las valorizaciones inmobiliarias generadas por la acción urbanística y los consorcios urbanísticos, buscan intervenir sobre los procesos de producción y crecimiento de las ciudades, generando condiciones estructurales para el desarrollo de las políticas de vivienda y hábitat (Arenaza, 2012).

Dentro de estos últimos, el establecimiento de Zonas de Promoción Social ${ }^{35}$ implica la planificación de suelo urbano a futuro en tanto confiere a los municipios la definición de planes y normas específicas, ya sea para desarrollar procesos de regularización urbana y dominial como para urbanizar reservas de tierras en predios vacantes. En esa misma línea, crea el Programa de Lotes con Servicios, ${ }^{36}$ contrarrestando la tendencia generalizada a la escasez de oferta de tierra apta para la residencia de los sectores de menos recursos (Scatolini, 2014; CELS, 2015b).

Por otra parte, define instrumentos para limitar las prácticas especulativas de la propiedad privada, como el régimen de sanciones contra los inmuebles ociosos, ${ }^{37}$ declarando el parcelamiento y/o edificación obligatoria para baldíos y edificaciones derruidas o paralizadas, pudiéndose aplicar un gravamen especial sobre el inmueble, que será progresivo en el tiempo, e incluso declarar la utilidad pública y quedar sujetos a expropiación en caso de no cumplimentar la obligación. También incorpora la participación en las valorizaciones inmobiliarias generadas por la acción urbanística ${ }^{38}$ a través de la recuperación de plusvalías urbanas. ${ }^{39}$

Sin dudas, la creación de todos estos instrumentos no hubiese sido viable sin la reconceptualización del derecho de propiedad y su función social como garantía del derecho a la ciudad.

\section{Consideraciones finales}

El recorrido realizado por la normativa específica sobre regulación del suelo adoptada en los últimos años nos permite afirmar que se ha producido un avance en los marcos institucionales y programáticos para el desarrollo de políticas públicas que garanticen el derecho a la ciudad. A nivel federal, esta normativa representa, sin dudas, avances sectoriales (ambiente, tierra rural, etc.) y, en el contexto del fracaso de la sanción de una Ley de presupuestos mínimos de ordenamiento territorial,
33 Se destaca, además, la creación de programas vinculados a la producción de lotes con servicios y a la regularización dominial, como el Programa Social y Familiar de Tierras (Pro-tierra) y el Programa Familia Propietaria.

34 Tal como se describe en sus sucesivos artículos, estos suponen: en primer lugar, el derecho a un lugar adecuado para vivir que favorezca la integración a la vida urbana, el acceso a equipamientos sociales e infraestructura y servicios, el desenvolvimiento apropiado de actividades sociales y económicas y el usufructo de un hábitat culturalmente rico y diverso. En segundo, que la propiedad cumpla con su función social, respetando exigencias generales y regulaciones en la producción del hábitat que garanticen la calidad de vida, el uso ambientalmente sostenible del territorio y la justicia social. Seguidamente, que la ciudad se gestione a partir de un proceso de toma de decisiones participativo, que asegure la deliberación y autogestión de la comunidad en general y de los ciudadanos en particular, especialmente de las organizaciones o asociaciones civiles que fomenten el acceso al hábitat. Finalmente, la utilización justa y razonable de la facultad regulatoria por parte del Estado, tanto provincial como municipal, en los procesos de planificación y ordenamiento urbano, evitando la producción de desigualdades que fomenten la concentración del suelo.

35 Ley 14449, Sección IV, artículos 44 y 45. 36 Ley 14449, artículo 17, Sección I. Promoción de procesos de producción social del hábitat y de urbanizaciones planificadas.

37 Normativa modificatoria a los artículos 84 al 90 y 92 del decreto-ley 8912 (art. $64)$.

38 Ley 14449, Sección V, art. 46 al 50.

39 Cabe señalar que algunos municipios ya venían incorporando normativa relativa a la participación en valorizaciones inmobiliarias, como el caso de Trenque Lauquen y Tres Arroyos; otros lo hicieron de manera progresiva a partir de la implementación de la ley, como en el partido de La Plata. 
no contempla la discusión sobre la regulación del suelo en el marco de una planificación integral del territorio.

La necesidad de adoptar una Ley de Ordenamiento Territorial se justifica no solo en el mandato constitucional que impone al Congreso la obligación de sancionar esta norma, sino también en una mayoritariamente vetusta legislación provincial y municipal, que debiera compatibilizar la regulación del suelo con los derechos y garantías consagrados en la última reforma constitucional, pudiendo servir de guía para fijar estándares mínimos. Ahora bien, sin perder esto de vista, también es cierto que la normativa adoptada incorpora limitaciones a la propiedad del suelo hasta entonces inexistentes.

Así, es posible matizar la idea de que no se ha puesto en cuestión la propiedad, estableciéndose diversos limitantes y condicionantes a la concentración del suelo y a la informalidad en instrumentos específicos como las leyes de Tierras, sobre la propiedad de Comunidades Indígenas y de Agricultura Familiar. Al fin y al cabo, como sostiene Levenzon (2014), el derecho a la ciudad, que en su origen se plantea como consigna política, ha ido avanzando hacia su reconocimiento como un derecho exigible, de la mano de un conjunto de instrumentos para viabilizarlo. En esta línea, sí cabe destacar la Ley de Acceso Justo al Hábitat sancionada en la Provincia de Buenos Aires, como marco regulador que establece modificaciones sustantivas al rol del Estado y del mercado en la planificación del territorio e incorpora el principio de la función social de la propiedad a las políticas urbanas y de vivienda, con el fin de garantizar el derecho a la ciudad.

Aun diferenciando la sanción de estos instrumentos legales de su efectiva implementación — que sería objeto de otra reflexión-, ellos se erigen como intersticios para disputar una progresiva democratización en el acceso al suelo para todos los sectores sociales, haciendo las veces de muros de contención frente a situaciones de emergencia, por ejemplo, relativas a la ejecución de desalojos.

Borja (2010, citado en Mathivet) plantea que el desarrollo del derecho a la ciudad supone un triple proceso: cultural, vinculado a lograr la hegemonía de los valores que se constituyen como basamento de estos derechos; social, relativo a los procesos de movilización para lograr su enunciación legal y efectivización; y político-institucional, en vistas a formalizarlos, consolidarlos y desarrollar políticas que los garanticen. En la normativa analizada esta tríada no se desarrolla de manera conjunta. Han sido los movimientos sociales, en articulación con otros actores, quienes han encabezado las demandas en pos de una legislación más inclusiva, presionando sobre el ámbito político-institucional. Por mencionar tan solo el ejemplo de la Ley de Acceso Justo al Hábitat, en el que las organizaciones de tierra y vivienda de la provincia jugaron un rol crucial, articulando con otros colectivos, universidades nacionales y el Gobierno provincial. Incluso a posteriori, una vez sancionada, cuando la disputa ya había ingresado a la esfera político-institucional, se reactivó el estado de movilización en pos de la efectiva reglamentación y contra la resistencia de algunos sectores que veían en los diversos instrumentos normativos un perjuicio para la defensa de sus intereses. Siendo así, diríamos que el componente cultural es justamente sobre el que resulta más difícil avanzar, pues implica poner en jaque la herencia de la cultura patrimonialista, anclada en la estructura de la propiedad de la tierra. Desde esa perspectiva, pareciera que se asume la existencia de un marco regulatorio rígido, anclado centralmente en el código civil, que impide avanzar en limitaciones a la propiedad. 


\section{Referencias}

Abramo, P. (2003). La teoría económica de la favela: cuatro notas sobre la localización residencial de los pobres y el mercado inmobiliario informal. Revista Ciudad y territorios: Estudios territoriales, XXXV, 136-137.

Arenaza, S. (2012). Propuestas de Reforma al Código Civil a la luz del Derecho a una Vivienda Adecuada. Lanús: Centro de Derechos Humanos, Universidad Nacional de Lanús.

Arenaza S. y Duarte J.I. (2010). ¿Por qué es importante para Argentina contar con una ley de ordenamiento territorial nacional? Revista Café de las Ciudades, 96. Recuperado el 10 de noviembre de 2016 de: http:/ / www.cafedelasciudades.com.ar/planes_97_2.htm.

Baer, L. (2016). Desarrollo urbano y movilización del suelo ocioso. Oportunidades y desafíos para la planificación de las ciudades del país. Revista Institucional de la Defensa Pública De la Ciudad Autónoma de Buenos Aires, 6, 67-77.

Bercovich L. (2012). Los que quedaron afuera, Revista Argentina de Teoría Jurídica, 13. Recuperado el 10 de noviembre de 2016 de: http://www.pensamientocivil.com.ar/system/files/bercovich.pdf.

Brenner, N. Peck, J. y Theodore, N. (2011). ¿Y después de la neoliberalización? Estrategias metodológicas para la investigación de las transformaciones regulatorias contemporáneas. Urban, 1, 21-40.

Canestraro, M.L. (2016). Sobre el derecho a la ciudad y el acceso al suelo urbano. Reflexiones a partir de intervenciones estatales recientes (Mar del Plata, 2012-2015). Revista de Geografia, CIG-IGEHCS-CONICET/UNCPBA, 20, julio-diciembre. Recuperado el 20 de abril de 2017 de: http:/ / docs.wixstatic. com/ugd/59a6db_1269e40eb456413dacfa371d23f b98c6.pdf.

- (2016). Sobre el derecho a la ciudad y el acceso al suelo urbano. Reflexiones a partir de intervenciones estatales recientes (Mar del Plata, 2012-2015). Estudios Socioterritoriales. Revista de Geografía.

Canestraro, M.L., Guardia, E. y Layus, E. (2014). Discusiones en torno a la recuperación de plusvalías urbanas: análisis de instrumentos en el Municipio de General Pueyrredón. Pampa. Revista Interuniversitaria de Estudios Territoriales, Universidad Nacional del Litoral (Argentina)/Universidad de la República (Uruguay), 10.

Centro de Estudios Legales y Sociales (2015a). Derecho a la tierra y a la vivienda, aportes al consenso nacional para un hábitat digno. Buenos Aires.

- (2015b). Una perspectiva de derechos sobre las politicas de desarrollo y de acceso justo al hábitat. En Derechos humanos en Argentina. Informe Anual. Buenos Aires.
Clichevsky, N. (2001). La captación de plusvalias urbanas en la Argentina: ¿futuro instrumento de equidad social? En Smolka M. y Furtado F. (eds.), Recuperación de Plusvalias en América Latina. Alternativas para el desarrollo urbano. Instituto de Posgrado e Investigación/ Pontificia Universidad Católica de Chile y Lincoln Institute of Land Policy. Eurelibros.

- (2003). Pobreza y acceso al suelo urbano. Algunos interrogantes sobre las políticas de regularización en América latina. Documento CEPAL, Serie Medio Ambiente y Desarrollo, 75, diciembre.

Cravino, M.C. (2006). Mercado inmobiliario y producción de la informalidad urbana en la Ciudad de Buenos Aires. Bogotá: VI Seminario Nacional de Investigación urbano regional ACIUR.

Duhau, E. (2002). Dimensiones socio-politicas de la irregularidad y la regularización de los asentamientos populares. Paper presentado al Lincoln Institute of Land Policy, Mimeo.

Durand-Lasserve, A. (1997). Prólogo. En Azuela, A. y François, T. (coords.), El acceso de los pobres al suelo urbano. México: CEMC-UNAM.

Fernandes, E. (1998). Direito do Urbanismo: entre a "cidade legal" e a "cidade ilegal". Em Fernandes, E. (org), Direito Urbanístico. Belo Horizonte: Del Rey.

- (1999). Redefining property rights in the age of liberalization and privatization. Land Lines, 11, 6 .

- (2003). Perspectivas para a renovação das políticas de legalização de favelas no Brasil. En Abramo, P. (org), A cidade da informalidade. O desafio das cidades latinoamericanas. Rio de Janeiro: Livraria Sette Letras, FAPERJ.

Fernández, W.R. (2012). Tierra y suelo urbano en una sociedad patrimonialista. En AA.VV., Derecho al suelo y a la ciudad en América Latina. La realidad y los caminos posibles. Montevideo: TRILCE-Centro Cooperativo Sueco.

Habitar Argentina (2012). Por un Código Civil y Comercial que proteja el derecho a la vivienda y a la tierra y habilite la mediación estatal en las relaciones privadas en un país que se aleja del neoliberalismo. Recuperado el 10 de noviembre de 2016 de: https:/ / 1.facebook. com/l.php?u=https $\% 3 \mathrm{~A} \% 2 \mathrm{~F} \% 2$ Fsites.google.com $\%$ 2Fsite $\%$ 2Fjornadashabitat $\%$ 2Farv $\%$ 2Fccychabita rfinalpd.pdf $\% 3$ Fattredirects $\% 3 \mathrm{D} 0 \% 26 \mathrm{~d} \% 3 \mathrm{D} 1 \& \mathrm{ch}=\mathrm{z}$ AQHgNQXd.

Harvey, D. (2004). El "nuevo" imperialismo: acumulación por desposesión”. Buenos Aires: Socialist Register; Consejo Latinoamericano de Ciencias Sociales.

- (2008). El derecho a la ciudad. Documento de Habitat International Coalition. Recuperado el $10 \mathrm{de}$ noviembre de 2016, de: http://www.hic-net.org/ content/david\%20harvey.pdf. 
Hermann Guttner, C. (2012). Comentarios a la Ley 26737 de "Régimen de Protección al Dominio Nacional sobre la Propiedad, Posesión o Tenencia de las Tierras Rurales", Id SAIJ: DACF120019. Recuperado el 10 de noviembre de 2016 de: http:/ / www.saij.gob.ar/doctrina/dacf120019-guttner-comentarios_ley_26737_ regimen.htm.

Informe anual del Consejo Provincial de Vivienda y Hábitat (2015).

Levenzon, F. (2014). El derecho a la ciudad y reformas legales en Argentina y América Latina. XI Simposio de la Asociación Internacional de Planificación Urbana y Ambiente (UPE 11). La Plata: Facultad de Arquitectura y Urbanismo.

Lorenzetti, P. (2012). Compatibilización entre la esfera pública y la privada y entre el ámbito colectivo y el individual, en el Código Civil y Comercial de la $\mathrm{Na}$ ción. SJA 2015/09/30-3, JA 2015-III. Recuperado el 10 de noviembre de 2016 de: http:/ / www.nuevocodigocivil.com/wp-content/ uploads/2016/04/Compatibilizaci\%C3\%B3nentre-la-esfera-p \% C3\%BAblica-y-la-privada-y-entre-el-\%C3\%A1 mbito-colectivo-y-el-individual-enel-CCyCN-por-Pablo-Lorenzetti.pdf.

Maldonado, M.M. (2004). La propiedad en la constitución colombiana de 1991. Superando la tradición del Código Civil. Material del Curso Profesional de Recuperación en plusvalías en América Latina, Lincoln Institute of Land Policy.

Maldonado, M.M. y Smolka, M. (2003). Las plusvalías en beneficio de los pobres: el proyecto USME en Colombia. Land Lines, 15, 3.

Mathivet, C. (2010). El derecho a la ciudad: claves para entender la propuesta de crear. Otra ciudad posible. En Sugranyes, A. y Mathivet, C. (eds.), Ciudades para tod@s. Por el derecho a la ciudad, propuestas y experiencias. Santiago de Chile: Habitat International Coalition.

Maurino, G. (2012). Derechos sociales fundamentales y bienes jurídicos protegidos en el Código. El caso de la vivienda. Revista Argentina de Teoría Jurídica, Escuela de Derecho-Universidad Torcuato Di Tella, 13. Recuperado el 6 de noviembre de 2016 de: http://www.utdt.edu/ver_contenido.php?id_ contenido=8440\&id_item_menu=5858.

Morales Schechinger, C. (2003). El debate por las reformas del suelo urbano en América latina. Documento presentado al Foro sobre Reforma urbana y desarrollo territorial: experiencias y perspectivas de aplicación de las leyes 9. a de 1989 y 388 de 1997, Colombia.

Rolnik, R. (1997). Legislación urbana y mercados informales de tierra en Sao Paulo, Brasil: el vínculo perverso. En A cidade e a lei: legislação, política urbana e territórios na cidade de São Paulo. São Paulo: Studio Nobel-Fapesp.

Salazar, C.E. (2012). Presentación. En Salazar, C.E. (coord.), Irregular. Suelo y mercado en América latina. México: El Colegio de México.

Scatolini, L. (2014). Habitar. Hacia un nuevo paradigma urbano. Buenos Aires: Facultad de Cs. Jurídicas y Sociales-Honorable Cámara de Diputados de la Nación.

- (2011). La prescripción administrativa: hacia la función social de la propiedad. Revista RAP Digital, 100-102.

Sili, M. y Soumoulou, L. (2011). La Problemática de la Tierra en Argentina. Conflictos y dinámicas de uso, tenencia y concentración. Fondo Internacional de Desarrollo Agrícola (FIDA).

Smolka, M. (2003). A regularização da ocupação do solo urbano: a solução que é parte do problema, o problema que é parte da solução. En Abramo, P. (org.), A cidade da informalidade. O desafio das cidades latino-americanas. Rio de Janeiro: Livraria Sette Letras; FAPERJ.

Smolka, M. y Mullahy, L. (eds.) (2007). Perspectivas urbanas. Temas críticos en políticas de suelo en América latina. Estados Unidos: Lincoln Institute of Land Policy.

Tedeschi, S. (2012). El proyecto de Código Civil y la distribución de la riqueza. Revista Argentina de Teoría Jurídica, Escuela de Derecho-Universidad Torcuato Di Tella, 13. Recuperado el 28 de abril de 2017 de: http:/ / www.utdt.edu/ver_contenido.php?id_ contenido=8440\&id_item_menu $=5858$.

Viale, E. (2012). Exposición en audiencia pública convocada por la Comisión Bicameral para la Reforma, Actualización y Unificación de los Códigos Civil y Comercial de la Nación. Recuperado el 20 de junio de 2017 de: http:/ /ccycn.congreso.gob.ar/export/ hcdn/comisiones/especiales/cbunificacioncodigos/ponencias/buenosaires/pdfs/024_Ponencia_ Enrique_Viale.pdf. 


\begin{tabular}{|c|c|c|c|}
\hline \multicolumn{4}{|c|}{ Nivel nacional } \\
\hline Año & Tipo y número & Denominación & Objetivos \\
\hline 2002 & Ley 25675 & $\begin{array}{l}\text { General del } \\
\text { Ambiente }\end{array}$ & $\begin{array}{l}\text { Establecer los presupuestos mínimos para el logro de una } \\
\text { gestión sustentable y adecuada del ambiente, la preserva- } \\
\text { ción y protección de la diversidad biológica y la implementa- } \\
\text { ción del desarrollo sustentable. }\end{array}$ \\
\hline 2006 & Ley 26160 & & $\begin{array}{l}\text { Declarar la emergencia en materia de posesión y propiedad } \\
\text { de las tierras que tradicionalmente ocupan las comunida- } \\
\text { des originarias del país por el término de } 4 \text { años. Suspender } \\
\text { temporalmente los desalojos que afectan a estos colectivos. }\end{array}$ \\
\hline 2011 & Ley 26737 & $\begin{array}{l}\text { Régimen de } \\
\text { Protección al } \\
\text { Dominio Nacional } \\
\text { sobre la Propiedad, } \\
\text { Posesión o Tenencia } \\
\text { de las Tierras Rurales }\end{array}$ & $\begin{array}{l}\text { Determinar la titularidad, catastral y dominial, de la situa- } \\
\text { ción de posesión, bajo cualquier título o situación de hecho } \\
\text { de las tierras rurales, y establece las obligaciones que nacen } \\
\text { del dominio o posesión de dichas tierras. } \\
\text { Regular, respecto de las personas físicas y jurídicas extranje- } \\
\text { ras, los límites a la titularidad y posesión de tierras rurales, } \\
\text { cualquiera sea su destino de uso o producción. }\end{array}$ \\
\hline 2014 & Ley 27118 & $\begin{array}{l}\text { Reparación } \\
\text { histórica de la agri- } \\
\text { cultura familiar para } \\
\text { la construcción de } \\
\text { una nueva ruralidad } \\
\text { en la Argentina }\end{array}$ & $\begin{array}{l}\text { Declarar el interés público de la agricultura familiar, campe- } \\
\text { sina e indígena por su contribución a la seguridad y sobera- } \\
\text { nía alimentaria del pueblo, por practicar y promover siste- } \\
\text { mas de vida y de producción que preservan la biodiversidad } \\
\text { y procesos sostenibles de transformación productiva. } \\
\text { Crear el Régimen de Reparación Histórica de la Agricultu- } \\
\text { ra Familiar destinado al agricultor y a la agricultura familiar } \\
\text { y empresas familiares agropecuarias que desarrollen activi- } \\
\text { dad agropecuaria en el medio rural conforme los alcances } \\
\text { que se establecen en la presente ley, con la finalidad priori- } \\
\text { taria de incrementar la productividad, seguridad y sobera- } \\
\text { nía alimentaria y de valorizar y proteger al sujeto esencial de } \\
\text { un sistema productivo ligado a la radicación de la familia en } \\
\text { el ámbito rural, sobre la base de la sostenibilidad medioam- } \\
\text { biental, social y económica. }\end{array}$ \\
\hline 2015 & $\begin{array}{l}\text { Código Civil y } \\
\text { Comercial. } \\
\text { Artículo } 1897\end{array}$ & $\begin{array}{l}\text { Prescripción } \\
\text { adquisitiva }\end{array}$ & $\begin{array}{l}\text { La prescripción para adquirir es el modo por el cual el po- } \\
\text { seedor de una cosa adquiere un derecho real sobre ella, me- } \\
\text { diante la posesión durante el tiempo fijado por la ley. }\end{array}$ \\
\hline 2015 & $\begin{array}{l}\text { Código Civil y } \\
\text { Comercial. } \\
\text { Artículo } 1899\end{array}$ & $\begin{array}{l}\text { Prescripción } \\
\text { adquisitiva larga }\end{array}$ & $\begin{array}{l}\text { Si no existe justo título o buena fe, el plazo es de veinte } \\
\text { años. No puede invocarse contra el adquirente la falta o } \\
\text { nulidad del título o de su inscripción, ni la mala fe de su } \\
\text { posesión. También adquiere el derecho real el que posee } \\
\text { durante diez años una cosa mueble registrable, no hurtada } \\
\text { ni perdida, que no inscribe a su nombre pero la recibe del } \\
\text { titular registral o de su cesionario sucesivo, siempre que los } \\
\text { elementos identificatorios que se prevén en el respectivo } \\
\text { régimen especial sean coincidentes. }\end{array}$ \\
\hline 2015 & $\begin{array}{l}\text { Código Civil y Co- } \\
\text { mercial. Artículo } \\
1941 .\end{array}$ & Dominio Perfecto & $\begin{array}{l}\text { El dominio perfecto es el derecho real que otorga todas las } \\
\text { facultades de usar, gozar y disponer material y jurídicamente } \\
\text { de una cosa, dentro de los límites previstos por la ley. El do- } \\
\text { minio se presume perfecto hasta que se pruebe lo contrario. }\end{array}$ \\
\hline 2015 & $\begin{array}{l}\text { Código Civil y } \\
\text { Comercial. } \\
\text { Artículo } 1942\end{array}$ & Perpetuidad & $\begin{array}{l}\text { El dominio es perpetuo. No tiene límite en el tiempo y sub- } \\
\text { siste con independencia de su ejercicio. No se extingue, } \\
\text { aunque el dueño no ejerza sus facultades, o las ejerza otro, } \\
\text { excepto que este adquiera el dominio por prescripción ad- } \\
\text { quisitiva. }\end{array}$ \\
\hline
\end{tabular}




\begin{tabular}{|c|c|c|c|}
\hline \multicolumn{4}{|c|}{ Nivel nacional } \\
\hline Año & Tipo y número & Denominación & Objetivos \\
\hline 2015 & $\begin{array}{l}\text { Código Civil y } \\
\text { Comercial. } \\
\text { Artículo } 1943\end{array}$ & Exclusividad & $\begin{array}{l}\text { El dominio es exclusivo y no puede tener más de un titular. } \\
\text { Quien adquiere la cosa por un título, no puede en adelante } \\
\text { adquirirla por otro, si no es por lo que falta al título. }\end{array}$ \\
\hline 2015 & $\begin{array}{l}\text { Código Civil y } \\
\text { Comercial. } \\
\text { Artículo } 1944\end{array}$ & $\begin{array}{l}\text { Facultad de } \\
\text { exclusión }\end{array}$ & $\begin{array}{l}\text { El dominio es excluyente. El dueño puede excluir a extra- } \\
\text { ños del uso, goce o disposición de la cosa, remover por pro- } \\
\text { pia autoridad los objetos puestos en ella, y encerrar sus in- } \\
\text { muebles con muros, cercos o fosos, sujetándose a las normas } \\
\text { locales. }\end{array}$ \\
\hline 2015 & $\begin{array}{l}\text { Código Civil y } \\
\text { Comercial. } \\
\text { Artículo } 2114\end{array}$ & Superficie & $\begin{array}{l}\text { El derecho de superficie es un derecho real temporario, que } \\
\text { se constituye sobre un inmueble ajeno, que otorga a su titu- } \\
\text { lar la facultad de uso, goce y disposición material y jurídica } \\
\text { del derecho de plantar, forestar o construir, o sobre lo plan- } \\
\text { tado, forestado o construido en el terreno, el vuelo o el sub- } \\
\text { suelo, según las modalidades de su ejercicio y plazo de dura- } \\
\text { ción establecidos en el título suficiente para su constitución } \\
\text { y dentro de lo previsto en este Título y las leyes especiales. }\end{array}$ \\
\hline \multicolumn{4}{|c|}{ Nivel provincial } \\
\hline Año & Tipo y número & Denominación & Objetivos \\
\hline 1977 & Decreto-Ley 8912 & $\begin{array}{l}\text { de Ordenamiento } \\
\text { Territorial y Uso de } \\
\text { Suelo }\end{array}$ & $\begin{array}{l}\text { Fijar condiciones para la producción del suelo urbano, in- } \\
\text { troduciendo restricciones y exigencias en cuanto a la zonifi- } \\
\text { cación, el tamaño de los lotes y las obras de infraestructura. }\end{array}$ \\
\hline 2012 & Ley 14449 & $\begin{array}{l}\text { de Acceso Justo al } \\
\text { Hábitat }\end{array}$ & $\begin{array}{l}\text { Promover la generación y facilitar la gestión de proyectos } \\
\text { habitacionales, de urbanizaciones sociales y de procesos de } \\
\text { regularización de barrios informales. Abordar y atender } \\
\text { integralmente la diversidad y complejidad de la demanda } \\
\text { urbano habitacional. Generar nuevos recursos a través de } \\
\text { instrumentos que permitan, al mismo tiempo, reducir las ex- } \\
\text { pectativas especulativas de valorización del suelo. }\end{array}$ \\
\hline
\end{tabular}

Anexo 1. Normativa analizada. Fuente: elaboración propia.

Arenaza, M. S. y Canestraro, M. L. (2017). La regulación de suelo como componente del derecho a la ciudad (Argentina, 20042015). Hábitat y Sociedad, 10, 289-302.

<http://dx.doi.org/10.12795/HabitatySociedad.2017.i10.16> 